\title{
AUTONOMIA E INTERNET: BINÔMIO NECESSÁRIO PARA O CURSO A DISTÂNCIA DE TECNOLOGIA EM HOTELARIA DO IFCE
}

\author{
Luiz RéGis Azevedo Esmeraldo ${ }^{1}$, JÚlio CÉSAR FerReira Lima ${ }^{1}$ \\ ${ }^{1}$ Instituto Federal de Educação, Ciência e Tecnologia do Ceará (IFCE) \\ <regisazevedo@gmail.com><julioepedrita@gmail.com>
}

DOI: $10.21439 /$ conexoes.v12i3.1266

\begin{abstract}
Resumo. Com a chegada do século XXI e a socialização da Internet, a Educação a Distância (EaD) consolida-se como uma modalidade de ensino usada no mundo inteiro. No entanto, percebe-se que muitos aspectos ainda necessitam de estudos para identificação e correção de problemas, bem como entender a maturidade cognitiva de alunos e de professores, no que se refere às metodologias exigidas no ensino a distância. A autonomia e as tecnologias da informação e comunicação (TICs) são fatores imprescindíveis para o bom desempenho do aluno na EaD. O objetivo geral desse estudo é descrever a influência das TICs na autonomia dos alunos, em especial a Internet, do curso de Tecnologia em Hotelaria do Instituto Federal de Educação, Ciência e Tecnologia do Ceará (IFCE), modalidade a distância. Já os objetivos específicos são determinar os recursos tecnológicos utilizados pelos alunos como instrumentos para garantir a autonomia do ensino a distância e estabelecer a percepção dos alunos do curso supracitado quando utilizam estas ferramentas. Este artigo é resultado de uma revisão bibliográfica, documental e webgráfica para um estudo exploratório descritivo, com análise quali-quantitativa e enfoque socioeducacional. Como instrumento de pesquisa utilizou-se um questionário aplicado com discentes. Concluiu-se que os alunos, do curso de Tecnologia da Hotelaria do IFCE utilizam todas as ferramentas disponíveis na plataforma digital, além de outras como e-mail, WhatsApp, facebook; e estão satisfeitos com os resultados quanto às exigências do curso.
\end{abstract}

Palavras-chaves: Educação a distância. Autonomia. Internet. Ensino-aprendizagem.

\section{AUTONOMY AND INTERNET: BINOMIAL NECESSARY FOR THE DISTANCE COURSE OF TECHNOLOGY IN HOSPITALITY AT IFCE}

\begin{abstract}
Reaching the 21st century and the socialization of the Internet, Distance Education (DE) is consolidated as a teaching method used worldwide. However, it is noticed that many aspects still need studies to identify and to correct problems, as well as to understand the cognitive maturity of students and teachers, regarding the methodologies required in the distance learning process. Autonomy and Information and Communication Technologies (ICTs) are essential factors for the good performance of the student in DE. The general objective of this study is to describe the influence of ICTs on the students' autonomy, especially the Internet, within the distance learning course of Technology in Hospitality at the Federal Institute of Education, Science and Technology from Ceará (IFCE). The specific objectives are to determine the technological resources used by students as tools to guarantee the autonomy of the distance learning process and to establish the students' perception when using these tools. This article is the result of a bibliographical, documentary and web-based review for a descriptive and exploratory study, with qualitative-quantitative analyses and a socio-educational approach. As a research tool, a questionnaire was used with students. It was concluded that the students from the course of Technology in Hospitality at IFCE use all the available tools in the digital platform, in addition to others such as e-mail, WhatsApp, facebook; and are satisfied with the results regarding the course requirements.
\end{abstract}

Keywords: Distance learning. Autonomy. Internet. Teaching-learning process. 


\section{INTRODUÇÃO}

Não há uma unanimidade quanto à origem de educação a distância (EaD). A literatura sobre o tema considera que as experiências de educação por correspondência iniciaram no final do século XVIII. Todavia, para entendimento prático e objetivo, são apontados como marcos iniciais da $\mathrm{EaD}$, o material oferecido pela Gazeta de Boston em 1728 com tutoria por correspondência, o instituto sueco Líber Hermondes de 1829 com curso de contabilidade e a primeira escola europeia por correspondência inaugurada no Reino Unido de 1840.

Vários fatores merecem destaques na evolução histórica do modelo de $\mathrm{EaD}$, entre os mais impactantes apresenta-se o desenvolvimento de serviços baratos e confiáveis de correio, que permitiam aos alunos a comunicação com seus instrutores. Essa facilidade permitiu o surgimento de instituições de ensino a distância que se tornaram clássicas no Brasil. Como exemplo pode ser citado o Instituto Universal Brasileiro, utilizando a TV e revistas de circulação nacional, como veículos de comunicação entre alunos e professores.

No entanto, o respeito à EaD só foi obtido em 1883 quando o estado de Nova Iorque autorizou o Chatauqua Institute, uma instituição de reconhecimento amplo, que usava o método a distância, para conferir diplomas a alunos formados na modalidade a distância. Outro marco significativo no reconhecimento da EaD como modalidade de ensino deu-se pela criação da Open University na Inglaterra em 1969, servindo de modelo para muitas instituições de ensino no mundo, interessadas em educação a distância. Mesmo havendo divergências quanto à primeira instituição e o primeiro curso a distância, a bibliografia é unânime quanto à importância da Open University como um marco e um modelo de sucesso, que tem destaque até hoje e atua exclusivamente com o ensino a distância.

Com o surgimento do computador pessoal e da Internet, a interação social entre alunos e professores foi facilitada, minimizando a distância social, bem como superando a dificuldade da distância geográfica. A $\mathrm{EaD}$ aproveitou estas mudanças desenvolvendo-se e adaptando-se às novidades, marcando um salto de qualidade e quantidade de usuários.

A modalidade educacional a distância preza pela democratização do conhecimento, que deve estar disponível a quem se dispuser a aderir, independente do lugar, do tempo e da instituição de ensino. Como aliado na formação do conhecimento tem-se a autonomia de docentes e discentes, que se faz mais destacada que no modelo tradicional de ensino presencial. Em virtude da distância geográfica e momento assíncrono de estudo entre os participantes dessa modalidade de ensino, esse conceito deve ser amplamente trabalhado, para sucesso no processo de ensino-aprendizagem.

Independentemente do tempo em que se percebe a $\mathrm{EaD}$, uma característica intrínseca a esta modalidade de ensino está na autonomia do aluno em estudar os conteúdos das disciplinas dos cursos, promovendo o autoaprendizado. Seja a comunicação através de jornais, como acontecia no século XVIII, ou através da Internet, a partir do final do século XX, o fato é que alunos e professores são gestores de seus estudos de acordo com suas rotinas, dos encontros presenciais e dos materiais disponíveis.

Daí a necessidade de um estudo mais apurado sobre a autonomia dos alunos na $\mathrm{EaD}$, onde a gerência dos professores é modificada, em virtude da disponibilidade de novas ferramentas digitais. Para orientar esse estudo foi levantado o seguinte questionamento: como as TICs, principalmente a Internet, influenciam a autonomia dos alunos do curso de Tecnologia em Hotelaria do IFCE? Quais são os recursos tecnológicos usados pelos alunos para auxiliar a autonomia no ensino? Os professores do Curso de Tecnologia do IFCE/EaD estão aptos a utilizar as TICs na percepção dos alunos?

Esta pesquisa tem como objetivo geral descrever a influência das TICs na autonomia dos alunos, em especial a Internet, do curso de Tecnologia em Hotelaria do Instituto Federal de Educação, Ciência e Tecnologia do Ceará (IFCE), modalidade a distância. Tem como objetivos específicos determinar os recursos tecnológicos utilizados pelos alunos como instrumentos para garantir a autonomia do ensino a distância e estabelecer a percepção dos alunos do curso supracitado quando utilizam estas ferramentas.

Como exposto no Projeto Pedagógico do curso de Tecnologia em Hotelaria do IFCE, modalidade a distância, o curso está vinculado ao sistema da Universidade Aberta do Brasil (UAB), fazendo parte da Diretoria de Educação a Distância do IFCE (DeaD/IFCE). O IFCE é uma autarquia federal, ligada ao Ministério da Educação. Criado de acordo com a Lei 11.892/2008, o IFCE possui características de instituição multicampi, especializada na oferta de educação profissional e tecnológica, atuando também nas áreas de pesquisa e extensão.

Ainda de acordo com o Projeto Pedagógico, o referido curso tem características de curso semipresencial, já que se exigem encontros presenciais nos polos de apoio, além dos encontros virtuais no Ambiente Virtual de Aprendizagem (AVA). As disciplinas que possuem carga horária de 02 créditos (quarenta horas no total) possuem um encontro presencial de quatro horas. As disciplinas com carga horária maior, de 04 créditos (oitenta horas no total), contam com dois encontros 
presenciais de quatro horas cada. O curso confere aos alunos graduação superior com titulação de tecnólogo em Hotelaria. Seu regime letivo é semestral por disciplinas com duração de 06 (seis) semestres, (03 anos). Para concluir o curso, o aluno tem que cursar obrigatoriamente uma carga horária de 2.040 horas. O curso acontece nas instalações dos polos de apoio presencial nos municípios que sediam o curso. A regularização do polo se dá mediante assinatura de Termo de Compromisso entre o IFCE, Prefeituras Municipais (responsáveis em manter o polo funcionando) e a Coordenação de Aperfeiçoamento de Pessoal de Nível Superior (CAPES).

\section{ELEMENTOS FACILITADORES DO ENSINO A DISTÂNCIA}

Os primeiros passos dados para a consolidação da $\mathrm{EaD}$, ainda no século XVII, utilizou o jornal como instrumento de divulgação dos cursos e de comunicação entre professores e alunos. O conteúdo programático e as tarefas das aulas eram veiculados neste meio de comunicação. A EaD vem beneficiando-se com a evolução dos meios de comunicação, apossando-se de cada avanço conquistado pela tecnologia, melhorando sobremaneira a interação entre os atores do processo de ensino-aprendizagem. Exemplo emblemático dessa benesse foi a utilização do rádio, logo depois da sua invenção, como novo meio de comunicação para essa modalidade de ensino. (GOLVÊA; OLIVEIRA, apud ALVES, 2011). Depois do rádio, veio a televisão que novamente proporcionou uma revolução na $\mathrm{EaD}$, uma vez que este veículo de comunicação além de transmitir o áudio, o que era característico do rádio, transmitia também as imagens, aumentando significativamente a recepção de informações pelos alunos da EaD.

No entanto, a interação aluno professor ainda era muito deficitária já que a comunicação tinha que ser feita após as aulas. Essa situação só melhorou com o aparecimento dos computadores e a socialização da Internet, quando alunos e professores puderam comunicar-se em tempo real trocando informações em formato de texto e imagens, ou até vendo um ao outro através dos monitores. Essa realidade transformou o pensar e o fazer dessa modalidade de ensino, confirmando o que havia acontecido através dos tempos, uma nova revolução no modelo de ensino a distância advinda de mais um avanço tecnológico.

A partir da tecnologia computacional, diversos recursos tecnológicos vêm podendo ser utilizados para diferenciar o estilo de aula, sem perder a essência educacional, o aprendizado significativo. Idoeta (2014) declara que "a tecnologia não precisa necessariamente revolucionar a aula: pode ser usada para ajudar professores e alunos a trabalhar conteúdos mais abstratos, por exemplo, ou facilitar o aprendizado." Para o autor, o sucesso da tecnologia auxiliando a educação passa obrigatoriamente por conexões com o mundo real do aluno através da personalização de alguns conteúdos e um planejamento estratégico (IDOETA, 2014). Assim, todo o potencial tecnológico poderá ser aproveitado, no sentido de desenvolver realmente o processo de ensinoaprendizagem dos atores envolvidos, com ganho qualitativo real para os discentes.

Porém, somente as TICs não garantem uma educação a distância de qualidade. É preciso ter um bom projeto pedagógico, além de uma equipe treinada. As instituições que trabalham com EaD devem investir em equipes multidisciplinares para fornecer subsídios pedagógicos e tecnológicos; na qualidade dos professores tutores, que são os responsáveis diretos pela discussão de conteúdos, exercícios e avaliações com os alunos; e em tecnologia, para que os cursistas tenham várias e atuais possibilidades de interação. A figura do professor é ressignificada, não se trata mais daquele detentor da informação que irá repassar ao aluno todo o conteúdo a ser aprendido. $\mathrm{O}$ docente deixa de ser professor expositor e passa a ser o professor transformador, aquele que orienta quais informações serão uteis para transformar o saber em fazer.

Há várias instituições no Brasil que oferecem cursos a distância. Em sua grande maioria essas instituições também trabalham com a modalidade de ensino presencial, sendo classificadas como dual mode. A variedade de cursos é também grande. Podem ser encontrados cursos de graduação e educação profissional em nível tecnológico, cursos de pós-graduação lato sensu, e até programas de mestrado e doutorado.

A EaD não é mais encarada apenas como uma alternativa ao aprendizado, mas como uma modalidade de ensino regular. Devido a esse fator, todo avanço tecnológico é bem vindo para auxiliar no processo de ensino-aprendizagem da $\mathrm{EaD}$, desde que devidamente desenvolvido e aplicado, objetivando o alcance de metas pré-estabelecidas. A utilização do computador e da Internet se inserem na EaD como ferramentas poderosas. A Internet é explorada como canal de comunicação em massa e de grande alcance apoiada em suas ferramentas tecnológicas de informação. Aliás, como declara ??), "a Internet é a base estruturante de todos os conceitos e de novas relações que compõe a sociedade em rede ou a cibercultura".

O mundo de conhecimento, pesquisa e discussão que se abre com a Internet, possibilita o acesso ao ensino a distância a um número cada vez maior de pes- 
soas em diferentes espaços físicos e que não obrigatoriamente estejam conectadas no mesmo espaço temporal. Aqui cabe uma reflexão sobre a sensibilização dos alunos sobre a quantidade de informações que eles acessam através da Internet, como também, a sua parcela de responsabilidade do seu próprio aprendizado, tema desse trabalho, a autonomia para o autoaprendizado.

Há um novo paradigma educacional neste século vivenciado por docentes e discentes onde uma nova consciência deve ser formada sobre o momento da aprendizagem. Os envolvidos no processo educacional devem estar conscientes da aprendizagem ao longo da vida, sendo seres adaptáveis na criação de novos cenários. O modelo de educação fragmentado e dividido não se aplica mais com a mesma eficácia de resultados. Devese considerar o novo paradigma da sociedade do conhecimento através da totalidade. Na sociedade contemporânea, a realidade experimentada pelos alunos não está unicamente ligada às vivências pessoais ou ao que é gerado pela família e escola. Como defende Moran (2007) p. 15), “[...] não existem modelos prontos e eles vão se adaptando ao novo, a cada situação que se apresenta”.

Como elemento facilitador dessa abrangência no processo de ensino-aprendizagem a autonomia individual aparece como grande aliada. A autonomia necessária na modalidade a distância é defendida por Paulo Freire em qualquer tipo de educação. Para Freire (1987), quando o sujeito aprende, está apto a construir sua própria autonomia crítica e participativa. Isso torna o educando agente do processo de ensinoaprendizagem, não o ser passivo do processo educacional do modelo tradicional, aqui entendido também como o ensino presencial, bastante difundido nas escolas brasileiras.

O ideal da modalidade de ensino a distância seria na verdade o que Serafini (2013, p. 76) acredita:

Cabe aos envolvidos nos cursos de EaD (professor, tutor, técnicos e toda equipe pedagógica) proporcionarem meios que despertem, no aluno, a curiosidade e as potencialidades de criar e construir o próprio saber, de forma que ele consiga se desvencilhar de todos os mecanismos de passividade envolvidos no processo de aprendizagem que lhe foram impregnados por uma educação behaviorista, mecanicista, instrucional, ou nos moldes industriais do fordismo, como ainda se vê, em alguns cursos a distância, uma forma de automatização do conhecimento.

Diversos recursos tecnológicos estão à disposição de alunos e professores para serem usados na educação. A autonomia do aluno deve ser considerada na escolha de recursos, conteúdos, assuntos e temas, mas sem menosprezar o papel do professor que passa a ser orientador dessas escolhas, contribuindo com o aluno para que não se perca no infinito mundo de informações disponibilizadas na Internet.
A EaD é um meio importante de ensino pela ação sistemática e conjunta de diversos recursos didáticos e pelo apoio de uma organização e tutoria que propiciem o aprendizado independente e flexível. Para Aretio (apud LOPES; NEWTON; SALVAGO, 2013, p. 2) uma das características da EaD é tornar:

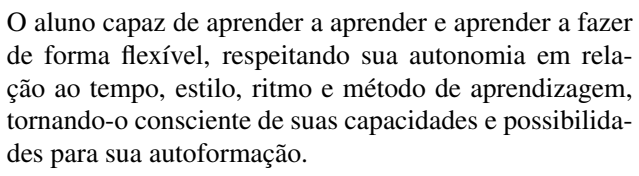

Demo (1988) comenta que a pesquisa como princípio educativo está ligada a autonomia. Para ele, esse conceito resume a definição de autonomia - a construção da metodologia do aprender a aprender (DEMO. 1988). À medida que o aluno se acostuma com pesquisa, ele passa a ser ativo na construção do seu conhecimento e passa a ter poder de decisão sobre sua aprendizagem. O trabalho com o objetivo de colocar o aluno como centro do seu aprendizado não é novo, mas é árduo, uma vez que o tipo de educação predominante no Brasil foi, e ainda é, a educação centrada no professor que possui o conhecimento e decide quando e como o mesmo será transmitido. Por sua vez, muitos dos alunos estão acostumados a esse modelo e desconhece (ou desconsidera) outro tipo de aula que não esteja dentro do modelo tradicional.

Com treinamento se oferece ao aprendiz ferramentas para se aprender mais eficazmente e tornar-se autônomo. Lógico que embora exista um elo dinâmico entre treinamento e autonomia, treinamento não pressupõe autonomia e autonomia é possível sem treinamento. Silva (2015) comenta que treinamento está relacionado ao conjunto de informações que possibilitam uma pessoa a desenvolver determinada tarefa, não obrigatoriamente, necessitando de formação profissional ou acadêmica. Em outras palavras, o treinamento permite autonomia para execução de tarefas, mas quase nunca autonomia para tomada de decisões. Por isso mesmo, o treinamento dos alunos para utilização das ferramentas da EaD, como o computador, permite autonomia no ensino, mas não autonomia nos conteúdos didáticos. Para tanto, há a figura do professor tutor para orientar o processo de ensino-aprendizagem no ensino a distância. É fundamental, portanto, que o professor possua conhecimento e domínio dos recursos tecnológicos disponíveis.

Importante, também, é frisar o pensamento de que autodidatismo não deve ser confundido com autonomia. Litwin (apud LOPES; NEWMAN; SALVAGO, 2013) ensina que o autodidata é o estudante que seleciona os conteúdos e não conta com uma proposta pedagógica e didática para o estudo. Já autonomia diz respeito a 
consciência de poder de realização e ao fazer, não ignorando ou dispensando a ajuda de um professor, quando necessária. Ao contrário do autodidata o aluno autônomo precisa cumprir com conteúdos e seguir a proposta pedagógica do curso.

Um sistema educacional que se diz adequado é formado por vários fatores. Primeiramente há o fator físico envolvendo as dependências estruturais da própria instituição e todo o material necessário ao funcionamento da mesma. Em seguida, chega-se ao fator humano formado por professores, colaboradores e alunos. Por último, mas não menos importante, há o fator imaterial que é a própria educação que deve circular por toda a instituição, ou seja, todos os elementos humanos presentes em uma instituição de ensino aprendem dia após dia.

Existem ainda instituições de ensino onde a tecnologia se apresenta na estrutura física e material e, usualmente, é utilizada pelo corpo discente somente. Já o corpo docente subutiliza tais avanços tecnológicos pela ignorância da manipulação e consequente resistência para adequação aos mesmos, causando muitas vezes hiatos na comunicação entre alunos e professores, prejudicando o processo de ensino-aprendizagem.

Ainda que o aparecimento dessas tecnologias date de meados do século passado, muitos professores ainda resistem à utilização de tais ferramentas no planejamento e execução de suas aulas. Dois fatores podem ser apontados como causa dessa deficiência, a saber: não há uma preocupação da inserção de disciplinas sobre TICs nos cursos de formação dos educadores e não há treinamento adequado subsidiado pelas instituições de ensino para que os professores resistentes possam ter conhecimento e desmistificar o "medo" da tecnologia, que muitas vezes ele é obrigado a conviver no ambiente de trabalho.

De acordo com Pinto (2004, p. 2):

A escola, enquanto instituição social, é convocada a atender de modo satisfatório as exigências da modernidade. Se estamos presenciando estas inovações da tecnologia é de fundamental importância que a escola aprenda os conhecimentos referentes a elas para poder repassá-los a sua clientela; $[\ldots]$

Clientela aqui é entendida como sendo os alunos das instituições de ensinos de diferentes níveis. Mesmo assim, para a modernidade e os avanços tecnológicos atingirem os alunos com mais eficiência, deve necessariamente haver uma adequação dos professores. É fundamental, pois, que professores formados com base em outro momento tecnológico, possam se disponibilizar a aprender a manipular as ferramentas da tecnologia da informação e comunicação atuais. Para tanto, cursos e treinamentos são fundamentais para um bom resultado.

\section{OBSTÁCULOS NO CAMINHO DA AUTONO- MIA}

Quando se fala em autonomia na educação, não se podem imputar somente aos alunos as dificuldades de desenvolver um estudo proveitoso. Também, e principalmente os professores, devem aprender a atuar usando a autonomia, uma vez que a formação desse profissional foi usualmente baseada em horários rígidos de aula e os atores do processo de ensino-aprendizagem, se encontravam no mesmo espaço físico, a sala de aula. Torna-se indispensável uma mudança de postura de ambos agentes.

Sendo a autonomia característica intrínseca da $\mathrm{EaD}$, cabem ponderações sobre este tema. Talvez o maior entrave no andamento inicial de um curso a distância seja o conceito, mal concebido, de que uma pessoa matriculada em um curso nessa modalidade de ensino não precise seguir um calendário de atividades. Essa é uma grande ilusão, existem prazos na $\mathrm{EaD}$ e esses devem ser cumpridos, sob pena do aluno não conseguir o número mínimo de presença e notas satisfatórias para lograr êxito nas disciplinas. Sendo assim, torna-se fundamental a autonomia do aluno na autoaprendizagem, não somente determinando os locais e horários dos estudos, mas também na escolha de temas, sejam dos conteúdos obrigatórios do programa, sejam de conteúdos complementares.

Para Ribeiro (2014), as metodologias estão intrinsecamente ligadas ao estudo da EaD. Elas exigem dos alunos uma postura de participação efetiva, garantido a sua autonomia no aprendizado. No intuito de facilitar a autonomia do aluno nesse processo, é necessário que se conheça melhor seu perfil, para estimular sua motivação e possibilitar sua participação eficiente na construção do seu aprendizado, em ambientes personalizados de aprendizagem. No ensino a distância, quando comparado ao ensino tradicional, o aluno muda de papel, passa de agente passivo, que, na maioria das vezes, recebe o conhecimento do professor pronto e acabado, para agente ativo do seu aprendizado, onde assumirá uma postura de pró-atividade na busca do conhecimento. Na verdade, o aluno passa a gerenciar o seu aprendizado, administrando o tempo, o ambiente e as ferramentas de estudo.

Com o advento da Internet, o aluno pode completar seu aprendizado formal ou informal, estando ele em qualquer local do planeta. Não é mais preciso estar na cidade ou país onde acontece o curso. Maia e Mattar (2007) chamam este estudante de aluno universal, isso porque ele pode cursar disciplinas em diferentes instituições espalhadas pelo mundo, podendo inclusive participar de cursos nas mais renomadas instituições como 
o Instituto de Tecnologia de Massachusetts (MIT), a Universidade de Harvard, a Universidade de Oxford, entre outras. O aluno pode participar de diversas instituições de ensino ao mesmo tempo, ou mesmo escolher aquela que melhor atende aos seus anseios. Os autores ainda comentam que surge na sociedade do conhecimento outra modalidade de aluno no ambiente da educação, o aprendiz virtual, aquele que está totalmente familiarizado com as TICs, as redes sociais, em outras palavras, com a web 2.0.

A flexibilidade na $\mathrm{EaD}$ não se restringe apenas ao local e horário de estudo. Conforme comentado anteriormente, os professores do ensino a distância também necessitam de disciplina para tratar a autonomia. Muitos professores que lecionam nessa modalidade falham no tempo de resposta às demandas dos alunos, seja para esclarecimento de dúvidas, para correção das atividades, ou ainda, para lançamento de notas.

O despreparo de professores e colaboradores que ingressam na $\mathrm{EaD}$ sem o embasamento devido sobre a modalidade, muitas vezes ocasiona índice elevado de desistência entre os alunos matriculados em cursos a distância. É importante ressaltar que evasão não é um aspecto problemático apenas de cursos a distância. A evasão escolar está presente também em cursos presenciais.

As altas taxas de evasão na EaD decorrem, segundo Bittencourt e Mercado (2014) de causas endógenas e causas exógenas. Entre as causas endógenas estão a didática dos professores, a ausência de tutores nos polos, critérios de avaliação dos discentes, a utilização de tecnologia inadequada proposta pelo curso, etc. Apontadas como causas exógenas estão discentes com dificuldades de acesso à Internet, dificuldade para deslocamento até o polo, problemas financeiros, mudança de endereço, falta de habilidade para usar as TICs, entre outras. Aqui se explicita a influência das TICs e do professor em um processo de ensino a distância de sucesso.

Maia e Mattar (2007) subentendem que o essencial nessa sociedade do conhecimento não é mais encher o aluno de informações, mas que os estudantes possuam capacidade de selecionar, através de pesquisas, as informações que são mais uteis para suas vidas e pretensões. Comentam ainda, que a reboque do ensino a distância surge um novo conceito de aprendizagem, o da heutagogia, aprendizagem autodirecionada em que o aluno passa a ser gestor e programador dos seus estudos. Neste caso o professor e a instituição passam a ser apoiadores no processo de ensino-aprendizagem. Os professores necessitam qualificar-se para a $\mathrm{EaD}$, já que esta modalidade exige práticas pedagógicas diferentes daquelas do ensino tradicional.
Lopes, Newman e Salvago (2013, p. 3) apresentam uma provável solução para os problemas citados acima quando diz que:

[...] Os professores deveriam capacitar-se para isso, principalmente quando esse ensino for feito a distância, via rede de computadores, por que suas características são diferentes daquelas a que estamos acostumados no ensino presencial. O professor, tanto no ambiente presencial como no ambiente on-line, sob a perspectiva da autonomia, precisaria estar disposto a ceder o controle e permitir que os aprendizes também participassem nas decisões no processo ensino-aprendizagem, e estes últimos precisariam estar dispostos a engajar-se e a ter responsabilidades em sua própria educação.

Referindo-se às diferenças entre os modelos de educação presencial e virtual, não podem ser esquecidas as experiências adquiridas dos docentes e discentes durante o processo de ensino-aprendizagem que já trazem consigo. Portanto, se faz necessário um período de transição e adaptação, para ambos os grupos de agentes do processo, buscando um melhor aproveitamento do ensino a distância, no que tange a autonomia no ensino. Para auxílio dessa transição, docentes e discentes devem receber orientações em relação ao modelo de ensino aprendizagem virtual, onde a autonomia se coloca como fator prioritário para se conseguir aprendizado permanente.

Considerando as diferenças do ensino presencial e do virtual, o professor ideal se faz presente quantitativa e qualitativamente nas interações, compensando a ausência de outras formas mais imediatas de trocas, como as que ocorrem na educação presencial. Não se pode confundir essa interferência do professor como um obstáculo, um engessamento da construção da autonomia do aluno, mas uma maneira de estar lado a lado, orientando e construindo com ele.

Como iniciadores do processo de aquisição de autonomia nos discentes, os professores devem mostrarse desenvoltos nessa questão através de uma autonomia moral e intelectual, proporcionando assim melhor qualidade do objeto que se pretende ensinar. É necessário que o professor disponha de habilidades, caso contrário será difícil ajudar os alunos a potencializarem suas capacidades cognitivas.

Por esses e outros obstáculos é que professores e alunos envolvidos em EaD devem estar conscientes da importância da autonomia como ferramenta facilitadora no processo de ensino-aprendizagem. As dificuldades devem ser analisadas e minimizadas considerando a autonomia como o centro das discussões, levando o entendimento de professores e alunos da necessidade do autoaprendizado, característica básica da modalidade do ensino a distância. 


\section{METODOLOGIA}

Como opção de método científico para esta pesquisa, buscou-se uma abordagem mista, quantitativa e qualitativa, situando-se num quadro de pesquisa exploratóriodescritivo. Esse quadro ocorre com a pesquisa junto aos alunos do Curso de Tecnologia em Hotelaria do IFCE, modalidade a distância, sobre o uso de ferramentas digitais disponíveis na Internet, como instrumento de apoio ao aprendizado (DIEHL; TATIM, 2004).

A pesquisa de caráter etnográfico virtual, que de acordo com Evans (apud PANIAGO; SANTOS; SILVA, 2016) busca construir uma etnografia utilizando o ambiente virtual, online, tem ainda natureza fenomenológica. Quanto aos procedimentos técnicos utilizouse a revisão bibliográfica, documental e webgráfica, buscando objetivos explicativos de perspectiva socioeducacional. A pesquisa com enfoque misto se utiliza da estatística e analisa a realidade de forma objetiva, como também explora os fenômenos.

$\mathrm{O}$ instrumento de coleta de dados utilizado foi o questionário disponibilizado na plataforma digital Google, sendo a primeira parte do instrumento contendo perguntas cujas respostas foram avaliadas quantitativamente, descrevendo o perfil socioeconômico dos alunos. A segunda parte continha perguntas cujas respostas apresentou análise de natureza qualitativa, inquirindo sobre a percepção dos alunos quanto à utilização das tecnologias na autonomia dos estudos e seus pontos de vistas sobre professores.

A pesquisa foi realizada no segundo semestre de 2017, entre os meses de agosto e outubro. Naquela data o Curso de Tecnologia em Hotelaria da UAB, registrava 120 (cento e vinte) alunos regularmente matriculados em nove polos presencias situados em cidades do interior do Ceará, onde aconteciam os encontros presenciais. As cidades eram Beberibe, Camocim, Caucaia, Itapipoca, Jaguaribe, Limoeiro do Norte, Meruoca, Quixeramobim e Tauá. O cálculo da amostra, com erro amostral de $5 \%$ e nível de confiança de $95 \%$, resultou em uma amostra de noventa e dois questionários. Todos os questionários enviados foram respondidos e devolvidos, servindo para posterior análise.

\section{RESULTADOS E DISCUSSÕES}

A primeira parte do questionário referia-se ao perfil dos entrevistados, onde se percebeu que $75 \%$ dos alunos do curso eram do gênero feminino, enquanto que $25 \%$ do gênero masculino. Quanto à idade dos entrevistados, a pesquisa mostrou que mais de $43 \%$ dos alunos estão entre 24 e 36 anos, significando que não se tratavam de alunos adolescentes, supondo-se, portanto, estarem mais preparados para a autodisciplina e para o autoaprendizado. Já quanto ao estado civil a grande maioria, $63 \%$ estavam solteiros e $22 \%$ casados. A pesquisa evidenciou que os alunos estavam dando os primeiros passos para vida profissional. Essa afirmação se justificou quando perguntado se o curso de Tecnologia em Hotelaria era a primeira graduação, obtendo resposta afirmativa em mais de $84 \%$ dos entrevistados cursavam seu primeiro curso de formação.

Sobre a inserção no mercado de trabalho, as respostas dos alunos mostraram que mais da metade, $64 \%$ dos entrevistados, estavam trabalhando, mas não necessariamente no setor da hospitalidade. O restante, uma parte significativa de $36 \%$ dos alunos não trabalhava no momento da pesquisa.

A Figura 1 mostra que dos alunos que trabalhavam, $39 \%$ recebiam entre $\mathrm{R} \$ 501,00$ e $\mathrm{R} \$ 1.500,00$ o que seria a média do salário mínimo brasileiro fixado em $\mathrm{R} \$$ 937,00 na época da pesquisa. Apenas $18 \%$ percebiam salários acima de $\mathrm{R} \$ 1.500,00$, sinalizando que mesmos os que ganhavam mais, ainda assim, apresentavam uma parcela abaixo da média salarial do brasileiro, que segundo o Instituto Brasileiro de Geografia e Estatística (IBGE) estava em R \$ 2,1 mil.

A pesquisa apresentou que $72 \%$ dos alunos residiam no distrito sede dos municípios, enquanto que $26,1 \%$ moravam na zona rural dos municípios. Dos entrevistados, 90\% possuíam computadores em casa, demostrando que não havia problemas com a aquisição de máquinas para acesso ao ambiente virtual de aprendizagem. Ainda sobre a acessibilidade digital, 75\% dos alunos possuíam banda larga em suas residências e $86 \%$ tinham smartphones com Internet. Estas respostas mostram que os alunos podiam acessar as aulas do polo presencial, de suas residências ou de outros locais como o de trabalho. A Figura 2 mostra a utilização dos smartphones nas disciplinas do Curso de Tecnologia em Hotelaria.

Quanto às ferramentas tecnológicas usadas no curso para acessar a Internet em suas residências, 67,4\% disseram que utilizam o celular como meio para acessar o ambiente virtual de aprendizagem (AVA) para responder mensagens, postar tarefas e participar dos fóruns das aulas. Com exceção da postagem de fóruns e tarefas, mostrando que $41 \%$ utiliza o celular, as demais atividades de mensagens, acesso a e-mails e aulas apresentou um percentual acima dos $60 \%$ em cada situação. Considerando que a resposta da pergunta sobre a utilização dos smartphones como acesso ao ambiente virtual de aprendizagem aceitasse várias escolhas, observou-se que as principais atividades da disciplina podem ser atendidas com o uso dessa ferramenta, con- 


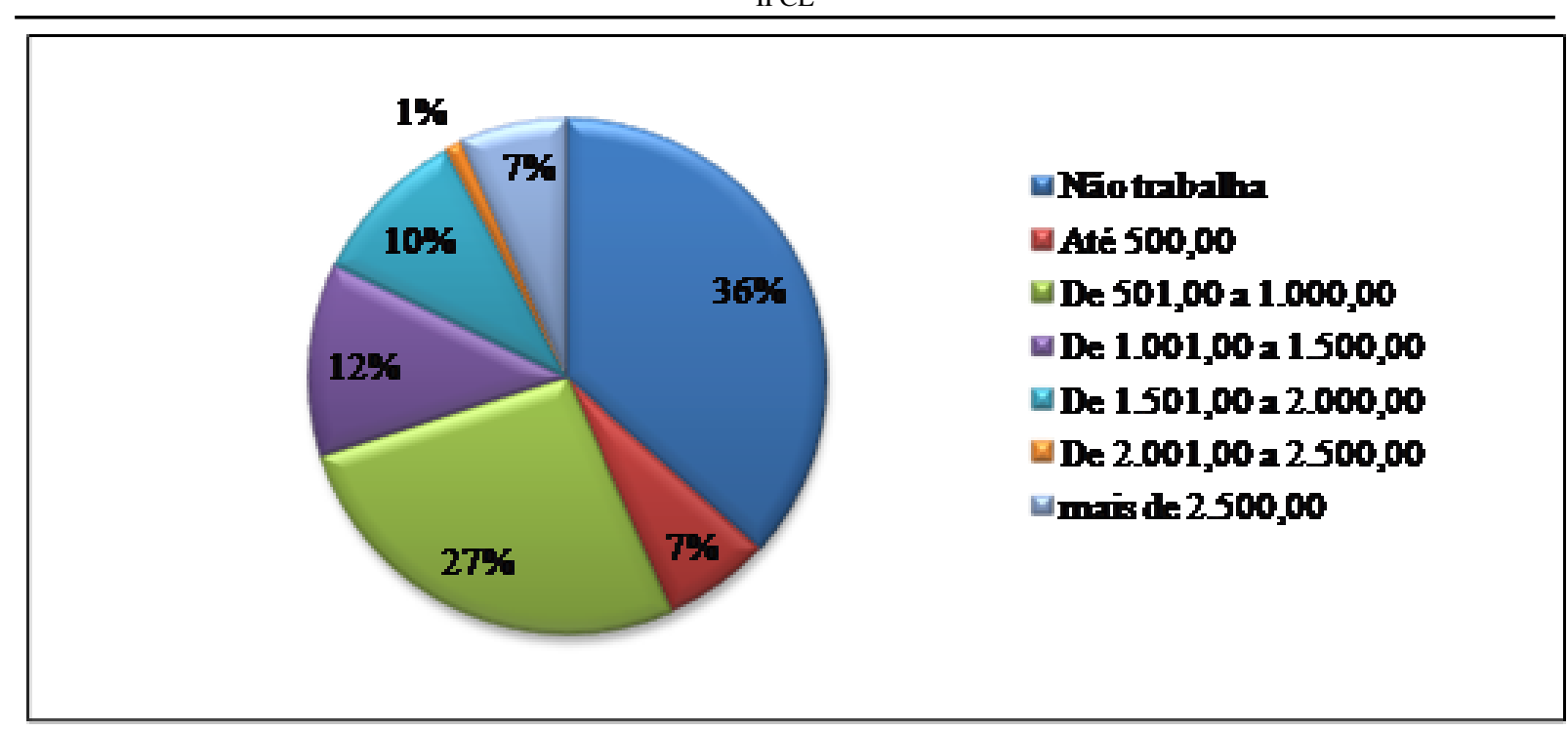

Figura 1: Faixa salarial em reais (individual) Fonte: Dados da pesquisa (2017)

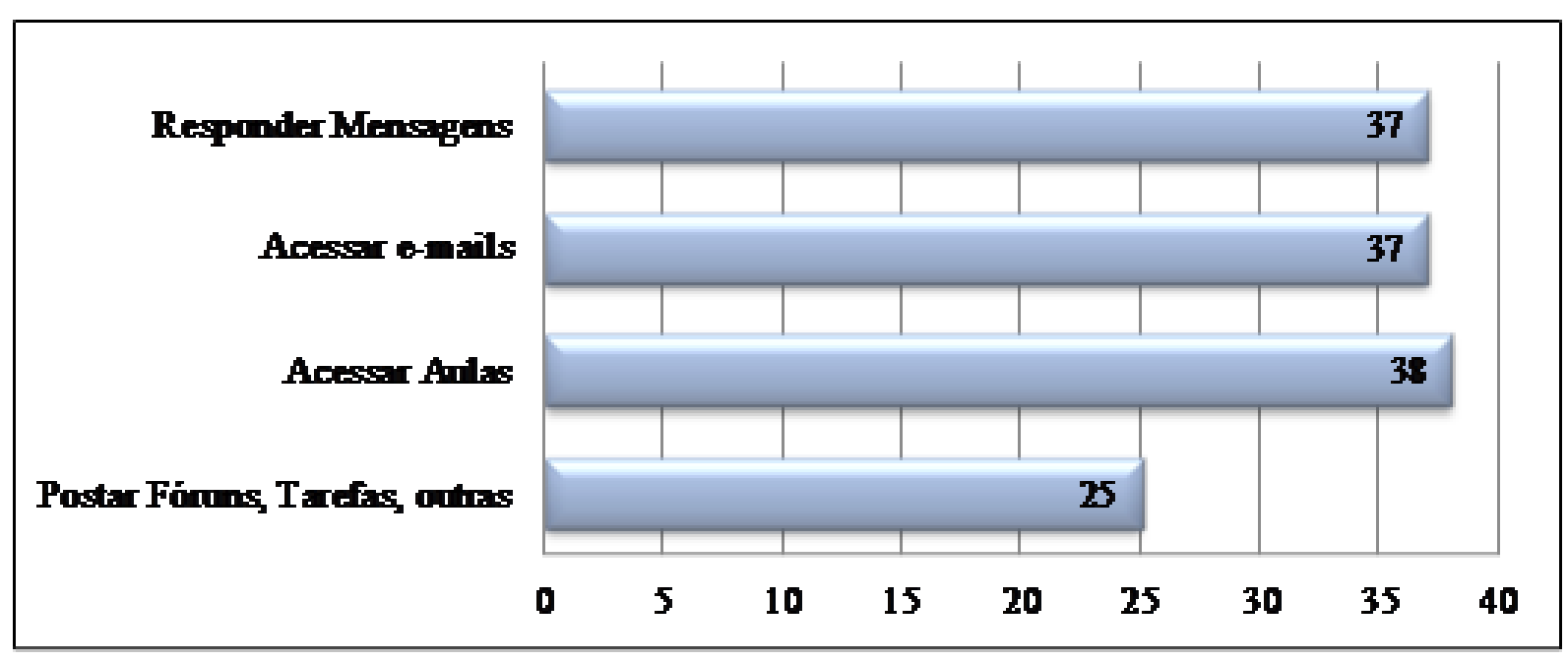

Figura 2: Utilização de smartphone.

Fonte: Dados da pesquisa (2017).

forme evidenciado na Figura 2. As respostas fortalecem a autonomia dos alunos, haja vista poderem levar consigo o celular e acessar o AVA, de acordo com sua conveniência.

Outra alegação que revela a autonomia dos alunos esta nas respostas da pergunta sobre dificuldades em acessar o ambiente da disciplina, quando $88 \%$ disse que não possuía nenhuma dificuldade em participar das atividades das aulas. Muitos dos alunos também utilizavam os computadores dos laboratórios dos polos, 56\% deles. No entanto, para essa pesquisa, mais importou a outra parcela de quase $50 \%$ que não utilizava os laboratórios, apontando para o uso de outras ferramentas em outros locais, que não o laboratório de informática dos polos.

A Figura 3 mostra os principais recursos tecnológicos usados pelos alunos para pesquisa e comunicação, ressaltando-se que o entrevistado poderia selecionar mais de uma opção.

As respostas da Figura 3 indica que os alunos demonstram autonomia para acessar o ambiente virtual de qualquer local e a qualquer hora, bastando ter sinal de 


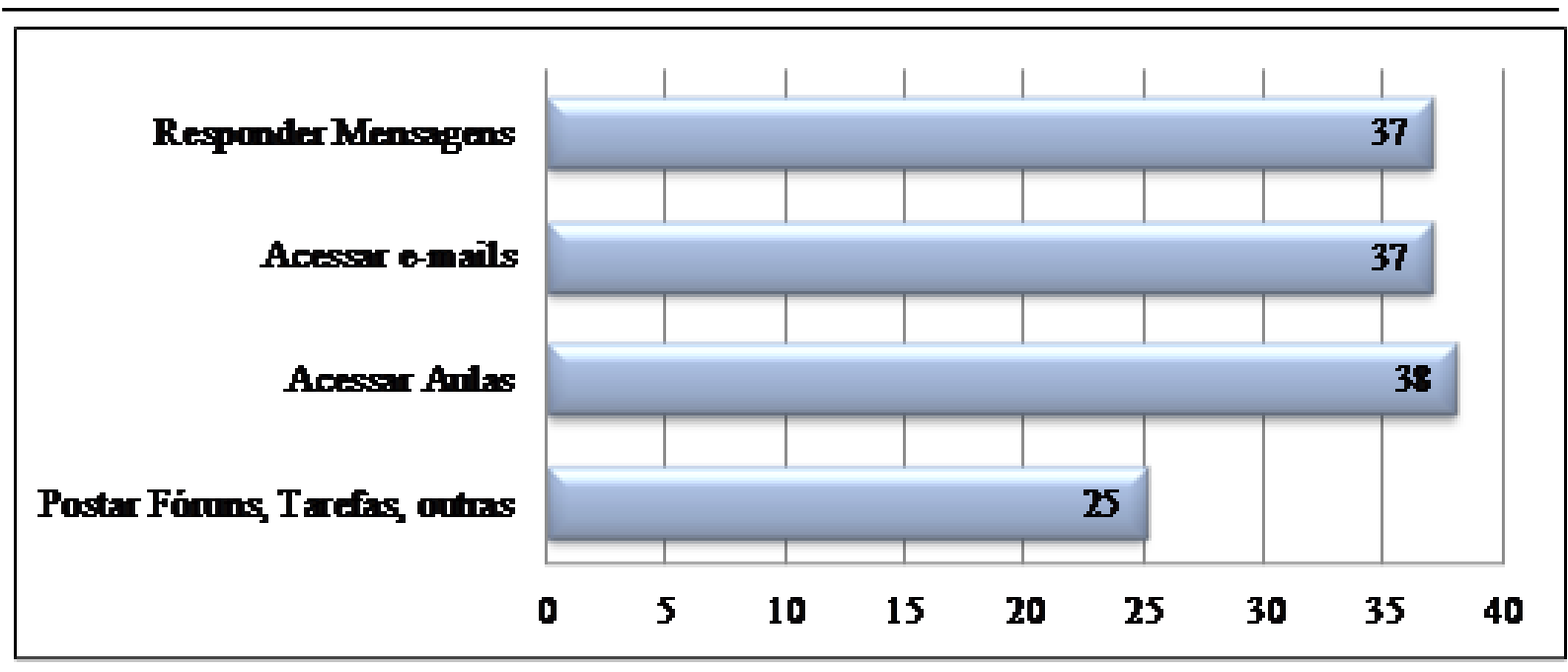

Figura 3: Recursos de pesquisa e comunicação. Fonte: Dados da pesquisa (2017).

Internet. Isso ocorre porque todos os recursos apresentados na pergunta podem ser acessados de um tablet, smartphone, notebook ou computador de mesa.

Quanto ao domínio dos professores sobre o ambiente virtual, a pesquisa apontou que na opinião dos discentes, $92 \%$ dos professores dominavam completamente os recursos tecnológicos disponíveis para pesquisa e comunicação, conforme mostra a Figura 4. Soma-se a esse valor, mais $7 \%$ dos alunos que declararam que o nível de domínio do AVA por parte dos docentes envolvidos era satisfatório. Chega-se, portanto, a 99\% de respostas positivas e infere-se, então, que os profissionais envolvidos com o curso pesquisado encontravam-se preparados tecnologicamente para utilização dos recursos disponíveis, consequentemente, alcançando resultados positivos em todo o processo de ensino-aprendizagem.

Por fim, a pesquisa evidenciou que $87 \%$ dos alunos não apresentavam dificuldades em acompanhar as aulas e os conteúdos do curso. A pesquisa também mostrou que $83,7 \%$ dos entrevistados estavam satisfeitos com os recursos tecnológicos disponíveis no curso de Tecnologia em Hotelaria do IFCE/EAD.

Os dados colhidos com as perguntas mostradas nesse artigo apontam para um aproveitamento positivo das TICs pelos envolvidos com o curso pesquisado. $\mathrm{O}$ corpo docente e o corpo discente estão cientes e também colocam em prática a autonomia para a construção dos conhecimentos necessários à formação do tecnólogo em Hotelaria proposto pelas diretrizes do curso em questão.

\section{CONSIDERAÇÕES FINAIS}

O ensino a distância vem consolidando-se a cada avanço tecnológico. Desde o início do século XX, quando se utilizava jornal, revista e correios para enviar material das disciplinas, a EaD vem modificandose. No início aconteceu com o surgimento do rádio e da televisão, permitindo um salto significativo na comunicação entre alunos e professores. No final do século passado, com o aparecimento dos computadores pessoais e a socialização da Internet, a EaD entra no mundo da interatividade quebrando todos os paradigmas do ensino a distância, iniciando uma nova era de comunicação.

O desafio então passou a ser o domínio das tecnologias por professores, alunos e colaboradores, e a adaptação dos conteúdos dos cursos a uma nova pedagogia, completamente diferente do ensino presencial tradicional. A quantidade de informações disponibilizadas na Internet descortina um novo problema: afinal o que realmente interessa ao aluno e professor para a construção do conhecimento? O papel do professor então é ressignificado deixando de ser o professor expositor, detentor da informação para ser o professor orientador, que conduzirá o processo de ensino-aprendizagem, estimulando principalmente a autonomia do aluno.

Em relação à autonomia é preciso salientar que se trata de uma conscientização de mão dupla. Primeiro os professores devem estar certos de que não são possuidores de todo conhecimento, a ser repassado em um curso ou disciplina. Em segundo, os alunos não podem pensar que por ter acesso a infinidade de informações dispostas na Internet são senhores do conhecimento. As opi- 


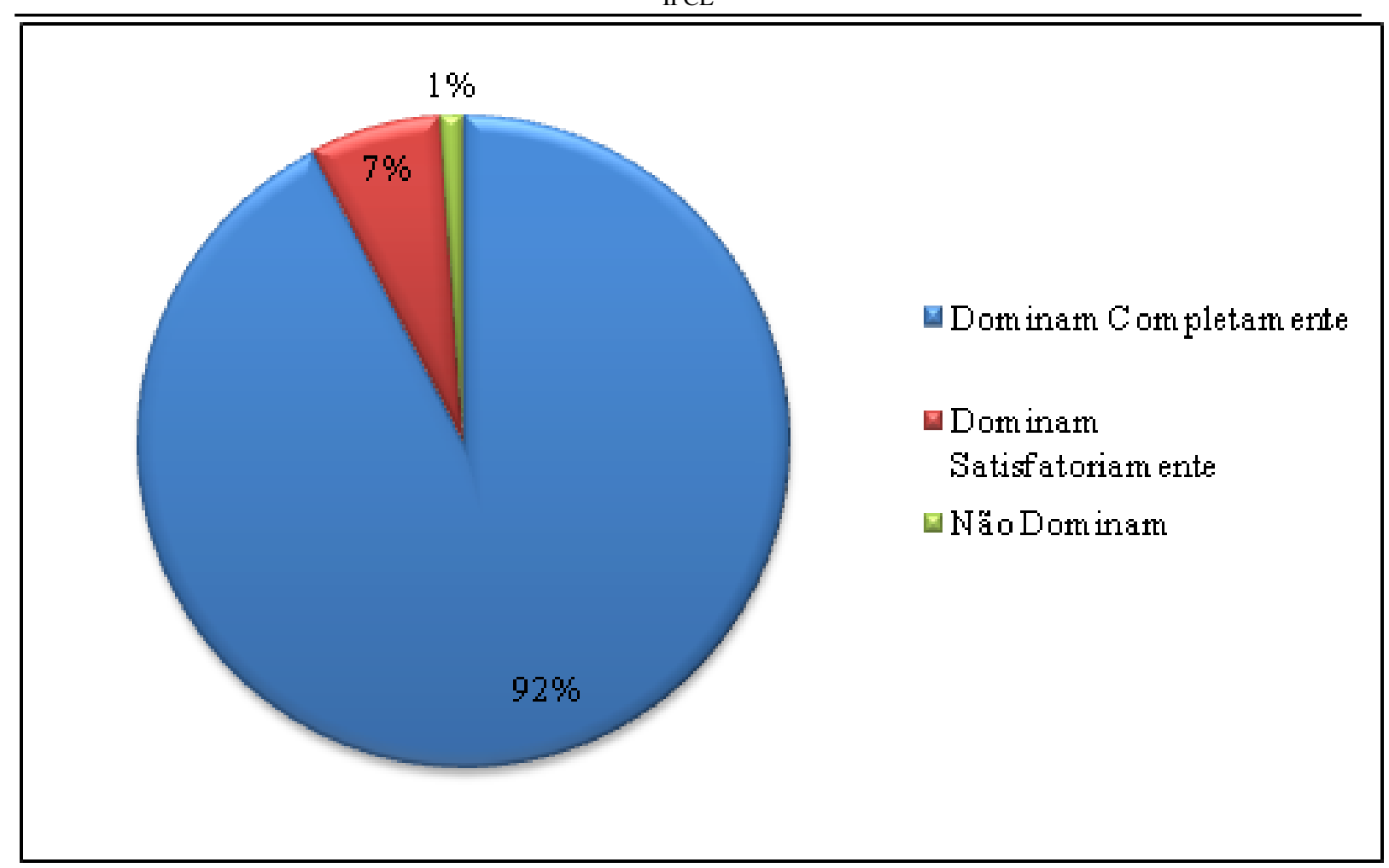

Figura 4: Domínio do AVA pelos professores. Fonte: Dados da pesquisa (2017)

niões e críticas dos alunos, relacionadas ao assunto que esteja sendo abordado durante as aulas, devem ser ouvidas e discutidas. Os professores devem estimular seus alunos a decidir sobre a construção do conhecimento direcionando-os na escolha das informações. O professor passa a ser o agente transformador quando conduz os alunos a análise, comparação, dedução, classificação e sintetização de ideias.

Com isso, inicia-se o processo de construção da autonomia do aluno através da orientação, metas e limites dentro do processo de autoaprendizagem. A proximidade entre professores e alunos é a grande diferença da EaD contemporânea. $\mathrm{O}$ advento da Internet encurtou as distâncias. Um contato mais rápido e eficaz pode ocorrer utilizando as ferramentas tecnológicas atuais, seja pra acessar conteúdos e assuntos, seja para a comunicação entre professores e alunos. Com essa afirmação, atingiu-se o objetivo desta pesquisa, quando foi mostrada a influência das TIC's na autonomia dos alunos no processo de ensino-aprendizagem. Esta influência evidencia-se quando $90 \%$ dos alunos possuem computadores em suas residências e $86 \%$ tem smartphones, indicando que possuem ferramentas de acesso aos conteúdos das disciplinas onde desejarem, garantindo uma autonomia tanto da hora e local do acesso, como também na escolha dos assuntos a pesquisar.

Quanto aos sites e aplicativos usados pelos alunos para leituras, comunicação e acesso a informações foram apontados como mais utilizados o e-mail e o WhatsApp, sem, no entanto, deixar de mencionar as mensagens postadas no AVA, facebook e hangout. O uso dos aplicativos permite uma relação mais profícua com o aprendizado, pela facilidade e flexibilidade, que estes aplicativos garantem. Importante mencionar, que não se pode determinar essas ferramentas como recursos oficiais do curso, haja vista a comunicação normalmente ocorre através de uma linguagem coloquial, por muitas vezes adaptada aos recursos dos aplicativos, com abreviações, sonoridades, figuras, entre outras. Estes sites e aplicativos devem contribuir no processo de ensinoaprendizagem, mas não substituir o AVA.

A maioria dos alunos possui Internet banda larga em suas residências, facilitando o acesso ao AVA e a comunicação, sem necessitar que o aluno tenha que se dirigir ao polo de apoio presencial para usar computadores e Internet dos laboratórios. A possibilidade de acesso nas suas próprias residências garante uma autonomia na escolha do horário do acesso às disciplinas do curso, tra- 
zendo mais comodidade. Como os alunos indicaram não ter dificuldades em acessar os conteúdos através da Internet, fica demonstrado que os mesmos dominam as ferramentas tecnológicas, fortalecendo a autonomia e dando segurança nas postagens das atividades das disciplinas.

O trabalho de conscientização e prática da autonomia educacional deve ser iniciado pelos próprios professores, responsáveis diretos pela educação dos alunos. Considera-se impossível desenvolver a autonomia dos alunos quando não há este entendimento presente nas práticas do corpo docente. Para tanto, é imprescindível que os professores dominem os recursos e aplicativos disponíveis sejam eles educacionais ou das redes sociais.

No século XXI, a tecnologia é efêmera, a quantidade de informações disponibilizadas para as pessoas está aumentando a cada hora, a autonomia no ensino, em especial no ensino a distância, será cada vez mais absorvida pelos alunos e professores. Outro ponto, que não se pode deixar de mencionar no final deste trabalho, como assunto para reflexão, é a inteligência artificial, que já é realidade na Internet. A Web 3.0 já está presente nos smartphones e computadores induzindo os usuários a comportamentos e necessidades analisados a partir dos acessos a Internet. Cabe, portanto, o aprofundamento das pesquisas, analisando como a autonomia das pessoas, sejam alunos ou professores, estará direcionada no futuro, com uma Internet mais inteligente a cada dia.

\section{REFERÊNCIAS}

ALVES, L. Educação a distância: conceitos e história no Brasil e no Mundo. 2011. Disponível em: <http://seer.abed.net.br/edicoes/2011/Artigo_07.pdf> Acesso em: 04 mar 2017.

BITTENCOURT, I. M.; MERCADO, L. P. L. Evasão nos cursos na modalidade a distância: estudo de caso do curso piloto de administração da UFAL/UAB. 2014. Disponível em: <http: //www.scielo.br/pdf/ensaio/v22n83/a09v22n83.pdf>. Acesso em: 04 out 2017.

DEMO, P. Ciência, ideologia e poder: uma sátira às ciências sociais. 1. ed. São Paulo: Atlas, 1988.

DIEHL, A. A.; TATIM, D. C. Pesquisa em ciências sociais aplicadas: métodos e técnicas. 1 . ed. São Paulo: Prentice Hall, 2004.

FREIRE, P. Pedagogia do oprimido. 1. ed. Rio de Janeiro: Paz e Terra, 1987.
IDOETA, P. A. Dez tendências da tecnologia

na educação. 2014. Disponível em: <http:

//www.bbc.com/portuguese/noticias/2014/12/141202 tecnologia_educacao_pai>. Acesso em: 24 jan 2017.

IFCE. Projeto pedagógico do curso de Tecnologia em Hotelaria -PPC / IFCE. Fortaleza (CE), 2007.

LOPES, M. C. L. P.; NEWMAN, B. A.; SALVAGO, B. M. Autonomia em contextos educacionais diferenciados: presencial e virtual. 2013. Disponível em: <http://www.vdl.ufc.br/solar/aula_link/extensao/ tutores/formacao_inicial_tutores/2013-1/LQUIM/ aula_03/imagens/02/aula02.pdf> Acesso em: 25 jan 2017.

MAIA, C.; MATTAR, J. ABC da Ead. 1. ed. São Paulo: Pearson Prentice Hall, 2007.

MORAN, J. M. A educação que desejamos: novos desafios e como chegar lá. 1 . ed. Campinas: Papirus, 2007.

s 2009]Simoes2009 O]ES, I. d. A. G. S. A sociedade em rede e a cibercultura: dialogando com o pensamento de Manuel Castells e de Pierre Lévy na era das novas tecnologias de comunicação. 2009. Disponível em: <http://www.insite.pro.br/2009/Maio/ sociedade_ciberespa\%C3\%A7o_Isabella.pdf $>$. Acesso em: 24 jan 2017.

PANIAGO, M. C. L.; SANTOS, R. M. R.; SILVA, K. A. G. Interações, diálogos, acolhimentos e negociações em uma formação continuada intelectual: uma abordagem de cunho etnográfico virtual. In: MARCIEL, C.; ALONSO, K.; PANIAGO, M. C. O. (Ed.). Interações entre sujeitos, plataformas e recursos. Cuiabá: EdUFMT, 2016.

PINTO, A. M. As novas tecnologias e a educação. 2004. Disponível em: <http: //www.portalanpedsul.com.br/admin/uploads/ 2004/Poster/Poster/04_53_48_AS_NOVAS_ TECNOLOGIAS_E_A_EDUCACAO.pdf $>$, Acesso em: 21 jan 2017.

RIBEIRO, R. A. Introdução à EaD. 1. ed. São Paulo: Perason Education do Brasil, 2014.

SERAFINI, A. M. d. S. A autonomia do aluno no contexto da educação a distância. 2013. Disponível em: <http://www.ufjf.br/revistaedufoco/files/2013/05/ artigo-031.pdf>, Acesso em: 24 jan 2017.

SILVA, P. C. O papel da educação corporativa na formação de empregados - o caso de uma escola 
AUTONOMIA E INTERNET: BINÔMIO NECESSÁRIO PARA O CURSO A DISTÂNCIA DE TECNOLOGIA EM HOTELARIA DO IFCE

voltada para técnicos. In: SOUZA, B. S.; SAMPAIO,

R. R. (Ed.). Educação, tecnologia e inovação (ORG).

Salvador: Edifba, 2015. 